\title{
Connecting Incoming Freshmen with Engineering through Hands-On Projects
}

Suxia Cui, Prairie View A\&M University, USA

Younhui Wang, Prairie View A\&M University, USA

Yonggao Yang, Prairie View A\&M University, USA

Felecia M. Nave, Prairie View A\&M University, USA

Kendall T. Harris, Prairie View A\&M University, USA

\begin{abstract}
Engineering programs suffer a high attrition rate, which causes the nation to graduate much less engineers. A survey of the literature reveals that the high attrition rate is due mainly to the fact that the first year of an engineering program is all fundamental theory and students don't see the connection to their future engineering careers. To address this problem, educators in the Roy G. Perry College of Engineering at Prairie View A\&M University launched a five-week summer camp entitled "College of Engineering Enhancement Institute (CE I)" aimed at improving the performance of incoming freshmen in mathematics by one level and a smoother transition between high school and college. Each department in the college participated by introducing their individual curriculum through hands-on projects designed by faculty members. Computer Engineering, Computer Science and Computer Engineering Technology programs implemented multimedia projects to tie the incoming freshman to their selected majors. Results show that the camp met the expectations and successfully points the directions for our future engineering education practices.
\end{abstract}

Keywords: Freshmen; Engineering Projects; Microcontroller; 3D Anaglyph Image; Video Game

\section{INTRODUCTION}

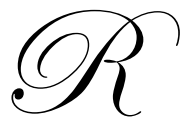

esearch shows the continuing decline of bachelor degrees awarded to domestic students in the natural sciences and engineering majors [1]. The lack of student motivation is identified as one contributor to some known problems such as high DWF (D-grade, withdrawal, and failure) rates reported by many institutions [2]. According to [3], undergraduates across the country are choosing to leave science, technology, engineering and math programs (STEM) before they graduate with those degrees, because many of them struggle to complete their degrees in four years, or drop out. A survey of the literature reveals that the major reason of engineering majors' dropout is because the first year of an engineering program is usually filled up with fundamental theory and students don't see the connection to their future career as engineers. This situation may be more profound for minority serving institutions where a larger number of the engineering students are the first in their families to pursue an engineering and/or technology degree. A relatively longer struggle with math, physics and chemistry courses along with the missing linkage of engineering practice result in students' losing interests before they have the opportunity to be enrolled in junior and senior years' program related core curricula. However, researches also indicate that, $93 \%$ of engineering degree holders started as an engineering major in their freshmen year, while only $60 \%$ graduates from other sciences majors retain their original choice of majors as freshmen [4]. This finding suggests that reducing dropout rates for engineering programs is more important comparing to other majors. Based on these observations, the authors of this article believe that besides attract more youngsters to engineering; another very important strategy is to keep them motivated throughout the freshmen year to cut down the high engineering programs' dropout rate. If both strategies are successfully implemented, the number of engineering graduates will be increased to maintain the U.S. competency and leadership in high-tech industries. Activities related to the first strategy include high school visits, middle school and high school summer camps. The 
second strategy focuses on incoming engineering freshmen. This paper shares an example of achieving the second strategy.

Statistics shows that the enrollment and retention rates of computer related majors are constantly dropping $[5,6]$ for the past decade. On the other hand, due to the aging workforce and emerging technology [7, 8], the industry demands for qualified graduates with expertise in computer science, computer engineering and technology are tremendous. The shortage of a qualified computer-related workforce in U.S. and the challenges to the U.S. technology dominance from fast growing foreign countries, like China and India, have led to more computing jobs being shifted abroad each year. This tendency will cause the U.S. to gradually lose its leading position in the computer industry. Thus it is our educator's responsibility to update the educational infrastructure to increase recruitment and enrollment to meet the challenge of global competency.

Recognizing the aforementioned problems, the administration and faculty in the Roy G. Perry College of Engineering (COE) at Prairie View A\&M University (PVAMU) worked together to design a rigorous high school to college bridge residential program for incoming freshmen. The College of Engineering Enhancement Institution $\left(\mathrm{CE}^{2} \mathrm{I}\right)$ builds on prior summer bridge programs offered by the College and the respective department as a strategy to prepare the students for the transition from high school to college and to practice engineering applications even before they enter the university programs. Students attended math, physics, chemistry, and computing classes during the day in order to lift them up to one higher level in those foundational theory courses before their first semester. In the evening, hands-on engineering projects designed by faculty from each engineering program were presented and performed to allow students to have a preliminary view of what they can do by completing their majors. Students spent two to three hours per day with their program advisors and student mentors to complete a project for a poster competition at the end of the camp. This paper presents the computer related projects generated by Computer Engineering, Computer Science, and Computer Engineering Technology programs, as well as the conclusions remarks. The above three programs are computer related programs under COE. All of the programs used multimedia technique as a tool to introduce computer application to freshmen. The background of this summer camp is introduced in the following section, followed by the detailed projects design and implementation. The summary and conclusions of this experience are shared at the end of this paper.

\section{OVERVIEW}

PVAMU, founded in 1876, is the second-oldest institution for higher-education in the state of Texas. During its 130-year history, PVAMU has established a reputation as one of the nation's top producers of AfricanAmerican engineers and has produced more African-American three-star generals than any other Historically Black College or University (HBCU) in the country. Belonging to the Texas A\&M University System, PVAMU is a stateassisted institution by legislative designation, serving a diverse ethnic and socioeconomic population, and a landgrant institution by federal statute. PVAMU is a predominantly undergraduate teaching institution with 6,021 undergraduates; as an HBCU, African-Americans constitute $90 \%$ of the undergraduate enrollment at PVAMU. PVAMU offers bachelor degrees in 50 academic majors, 37 master's degrees, and 4 doctoral degree programs through 9 colleges and schools. The COE of PVAMU has eight ABET accredited programs: Chemical Engineering, Civil \& Environmental Engineering, Computer Engineering, Computer Science, Computer Engineering Technology, Electrical Engineering, Electrical Engineering Technology, and Mechanical Engineering.

During the summer of 2009, the COE welcomed fifty-four (54) participants to the $\mathrm{CE}^{2} \mathrm{I}$ program in its inaugural year under the restructured format. This cohort of students represented approximately $21 \%$ of the incoming freshman class with $89 \%$ of the participants' reporting that they are residents of Texas. The average high school grade point average (GPA) of the participants was 3.285 with the average ACT and SAT being 20.5 and 1036, respectively. The GPA and ACT/SAT average is higher than the averages for the University and higher than the national test average for African American students (16.9-ACT/855-SAT) [9, 10]. Additionally, twenty-four percent of the participants reported that they were ranked in the top $10 \%$ of their graduating class.

At the start of the program, students were administered a Calculus I readiness Exam, which was developed and administered by the Math Department. The participants also were administered a Chemistry for Engineers pretest, which was developed and administered by the Chemistry Department. Based on their math placement exam 
scores, students were placed in either College Algebra and Trigonometry or Trigonometry. Thirteen or $24 \%$ of the participants were placed in Trigonometry with the remaining forty-one students placing in College Algebra and Trigonometry. Students were further enriched with Professional Development Sessions taught by corporate representatives (Bechtel, Career Services, Jacobs Engineering, Student Affairs, Shell Oil) as well as corporate field trips (Wal-Mart Distribution Center \& IBM). Students participated in discipline specific projects lead by faculty advisors (with the assistance of student mentors) from the respective departments. For the discipline specific projects, students were separated based on the major selected upon admission to the university. The students were grouped as follow: Chemical Engineering (12), Civil \& Environmental Engineering (13), Computer Science (4), Electrical Engineering (5), Computer Engineering (8), Computer Engineering Technology (4), and Mechanical Engineering (8).

\section{PROJECTS DEVELOPMENT AND IMPLEMENTATION}

As previous stated, computer education is facing a challenge of high drop rate. Several trials have been made to teach computer through multimedia including both computer related majors and non-computer related majors $[11,12,13]$. The scheme is to use high-end computer applications to explain computer concepts. Similar approaches have been successfully applied by researchers to teach computer or math classes to engineering students $[14,15]$. In fact, all these practices are designed for engineering students who are already in the programs and have basic knowledge on their specific majors. However, following this promising trend in pedagogy, a group of faculty members extended the benefit group to incoming engineering freshmen in the $\mathrm{CE}^{2} \mathrm{I}$ summer camp who had limited or no background of engineering.

Among all the camp participants, one third chose computer related majors: Computer Engineering, Computer Science, and Computer Engineering Technology. Faculty advisors from these three programs designed according hands-on practice projects with sound, image, or video game to facilitate incoming freshmen with a preliminary understanding of how computer contributes to our everyday lives. The following three projects are selected:

\section{Microcontroller Project - Computer Engineering}

Computer engineering is a discipline that embodies the science and technology of design, construction, implementation, and maintenance of software and hardware components of modern computing systems and computer-controlled equipment. Computer engineering has traditionally been viewed as a combination of both computer science (CS) and electrical engineering (EE) [16]. Computer Engineering utilizes both software and hardware knowledge, which is challenging among all engineering disciplines especially to incoming freshmen without background on either programming or electrical circuits. How to introduce the gist of this hybrid technology to this group of students is critical.

Microcontrollers are small, self-contained computers, and are the brains of lots of devices and appliances in our everyday lives. It is a very good example to introduce how computer engineering links both hardware and software together. The "Microcontroller Computer System Engineering Kit" by Thames \& Kosmos was chosen to be the platform which features a BASIC type programming module to avoid detailed programming language barrier for first time learner. Besides the microcontroller, it also introduces to students some basic circuit connection skills. Those elements include resistors, capacitors, diodes, virtual equipments, such as voltage meter, and oscilloscope. There is also a feature of infrared (IR) connection to the computer which provides convenient downloading process.

The whole project has three stages:

1. Introduce to computer engineering discipline.

2. Practice microcontroller skills by warming up with the microcontroller kits.

3. Students build a microcontroller system of their choice for a competition.

The first stage was conducted through lectures by a faculty advisor. The second stage was completed by exploring the examples provided from the training kits. Students had the opportunity to experience the temperature 
sensor, clap switch, motor control, and other systems. Finally, with the experiences they obtained, they were able to design their own microcontroller systems. Among the three different designs, a music beat generator, is a good example of their achievements. The circuit diagram, flowchart and circuit connection of the beat generator are briefly illustrated in Figure 1. This example invokes both sound and light as output devices. The software starts with one sample program which is a simple beep sound generator. By manipulating the delay time and the number of loops, students can perform their favorite song through this microcontroller training kit. A display of seven LEDs will also light up with the beat to make this generator more attractive.

During the summer project, students tried several sound and display examples. The results of the project showed that all the students were able to install and test the software. Also they could build their own circuits and made simple programs to make the hardware work. It was exciting to share the music piece and even dance with the beat at the end of the project. Through this project, students gained interests in computer engineering project and conquered the fear of programming since "computer programming language is a universal language just as music."

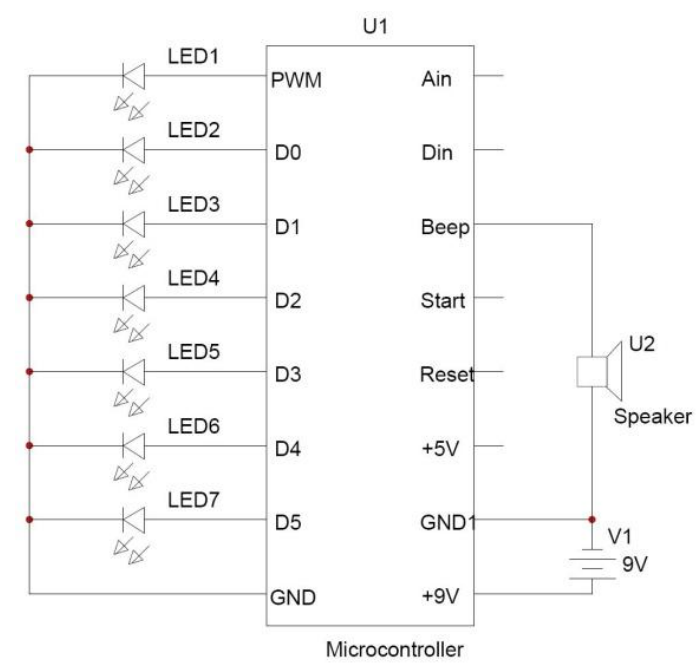

(a)

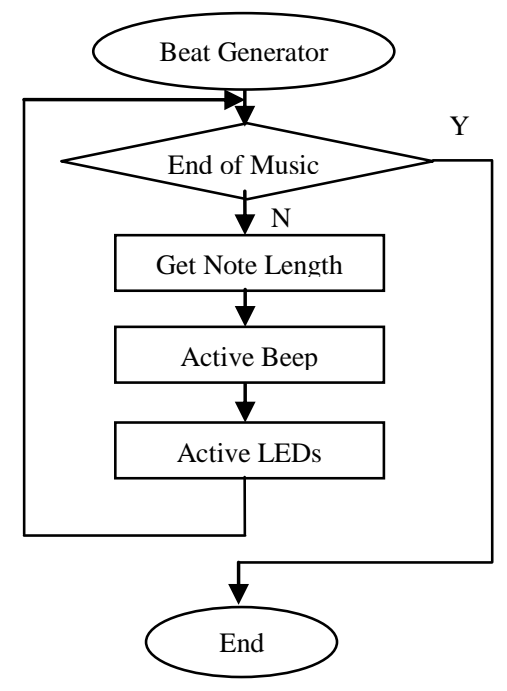

(b)

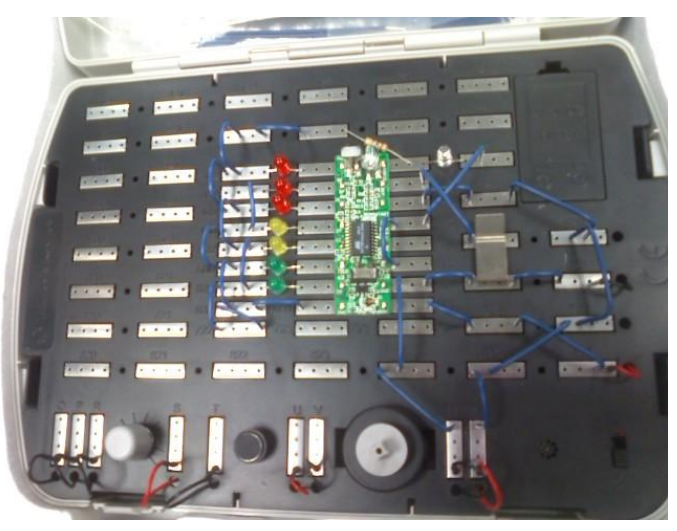

(c)

Figure 1: (a) Circuit Diagram; (b) Flowchart; and (c) Circuit on Training Board of a Beat Generator 


\section{3D Anaglyph Imaging Project - Computer Engineering Technology}

Nowadays computer technique has been widely used in movie effects. For example, most Hollywood recent productions go 3D with the help of computer graphics technology. Faculty advisors from Computer Engineering Technology program designed a project to unveil the mystery of how 3D images are produced. By exploring some basic concepts of 3D image processing technique and applications in this 3D anaglyph imaging project, students had an in depth understanding of how computer contributes to our daily lives from another view of point.

To prepare for the project, basic concepts of image processing [17] and anaglyph images are introduced in the lectures at the beginning. This project focus on creating 3D anaglyph images through digital image processing techniques. The definition of Anaglyph images in Webster dictionary is: "a stereoscopic motion or still picture in which the right component of a composite image usually red in color is superposed on the left component in a contrasting color to produce a three-dimensional effect when viewed through correspondingly colored filters in the form of spectacles."

The whole project has three stages:

1. Introduce computer engineering technology discipline and warm up with the image processing concepts.

2. Design a system which can produce anaglyph images. Students will also learn to make their own 3D glasses.

3. Build and test the system to acquire the results and present the project.

Figure 2 shows the block diagram of a 3D anaglyph image producing system. The two cameras (or one taking pictures from two different angles) simulate human eyes. The left camera takes a left view picture, while the right camera snaps a right view image. The two images are inputted into the computer, in which a student designed digital image processing program will impose them together to produce an anaglyph image. Then looking through two color glasses, people can see the image with the stereoscopic 3D effect.

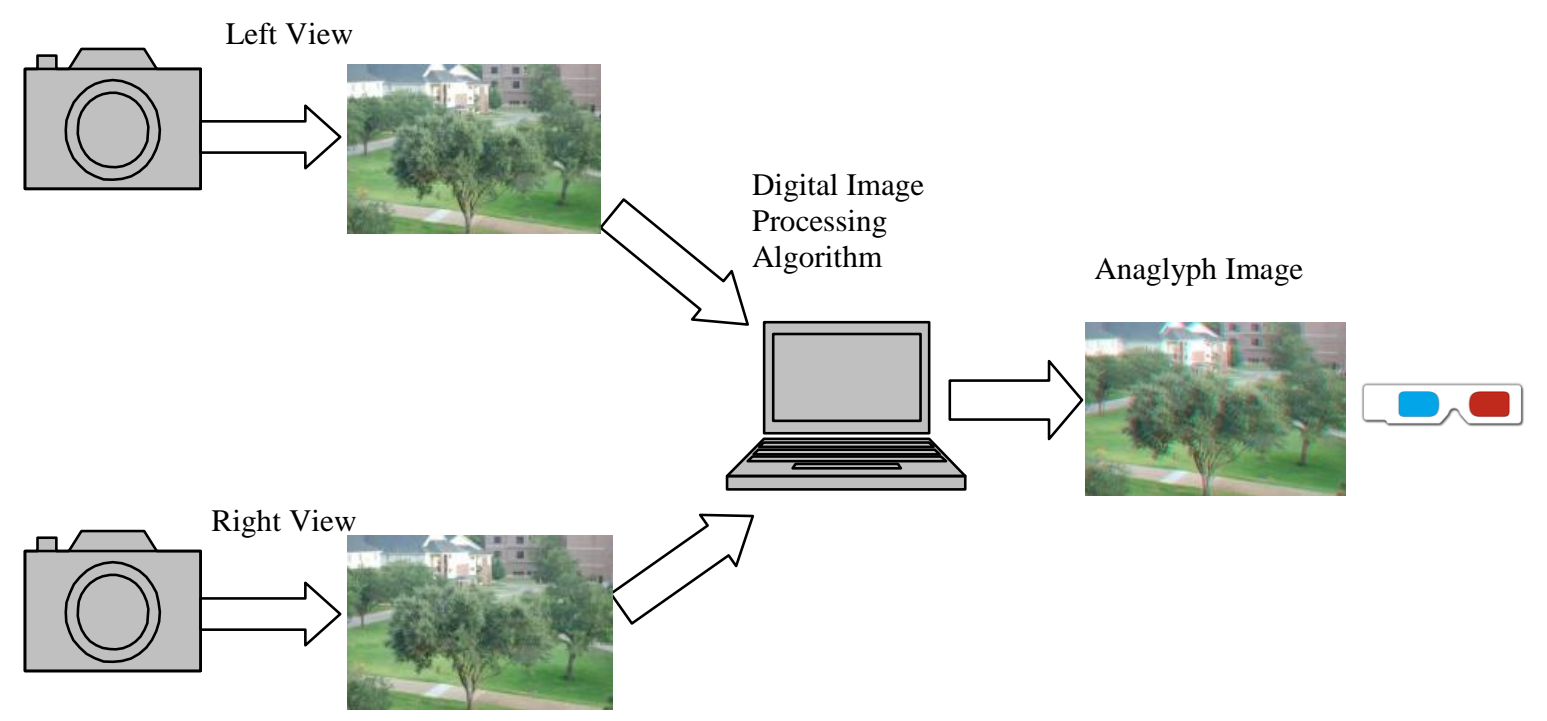

Figure 2: 3D Anaglyph Imaging System

At the beginning, presentations were given to the students to help them understand the basic theory lying behind the proposed project activities. Through examples, students learned the concepts and the procedure to make anaglyph images, as shown in Figure 2. After students gained basic understanding on how anaglyph images work as well as how we can produce such images, they learned simple Matlab programming. They practiced on how to 
combine the two view images into one anaglyph image using Matlab program, as shown in Figure 3, and wrote the program with the guidance from faculty advisor and student mentor:

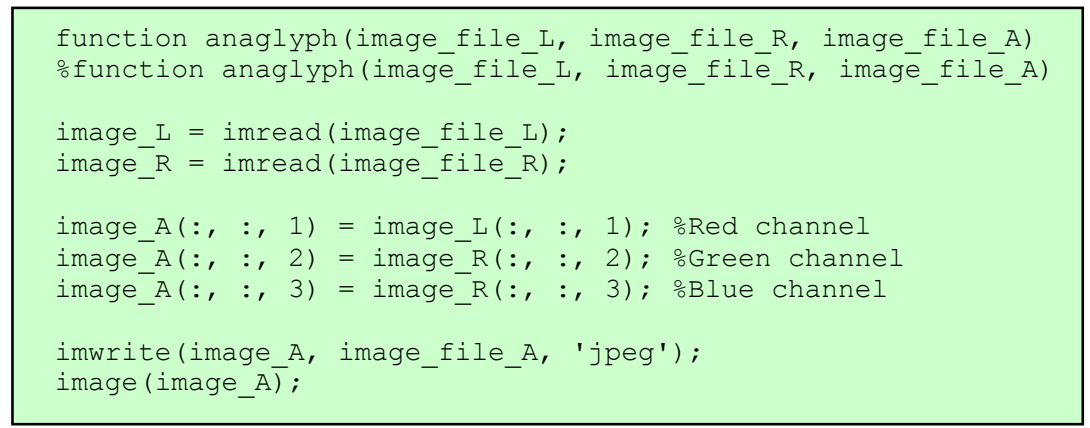

Figure 3: Matlab Program of Anaglyph Project

They then learned how to take the left and right view images using a single camera. Figure 4 shows several anaglyph examples generated by students. After gaining interests through this hands-on project, students were excited about the anaglyph images they made from surrounding objects. It is worth to mention that this group of students won the first place in the project poster contest at the end of the camp.
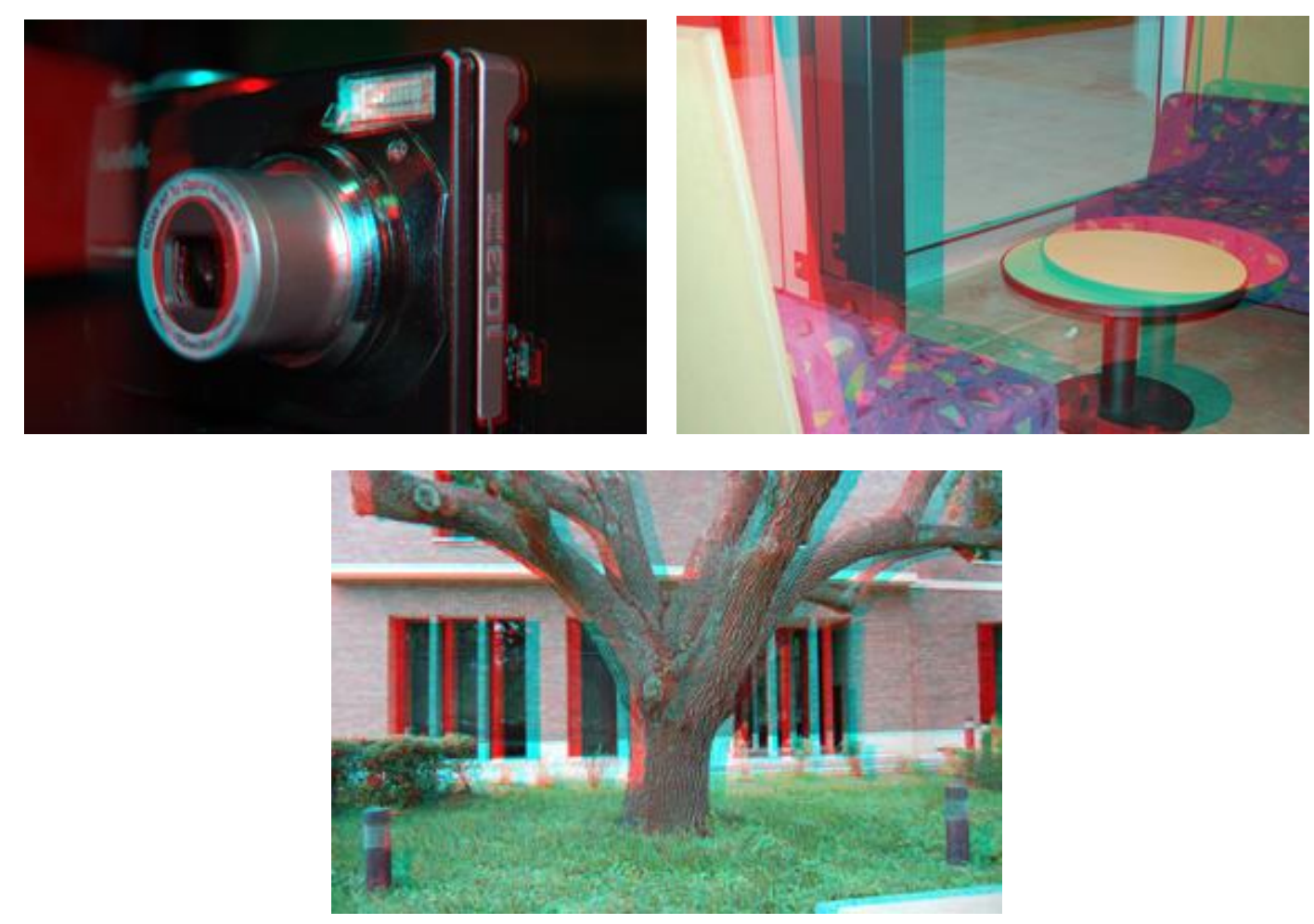

Figure 4: Students' Anaglyph Images

\section{3D Game Project - Computer Science}

With the help from a CS faculty, this CS incoming freshmen project team decided to develop a computer program (a 3D game) and got to understand computer software development life cycle: analysis, design, 
implementation/coding, documentation/testing, and deployment/operation/maintenance (as shown in Figure 5). The project objectives were set to (a) foster students' ability to work collaboratively and effectively as a part of a team; and (b) learn simple computer programming language and how to use it solve real problems.

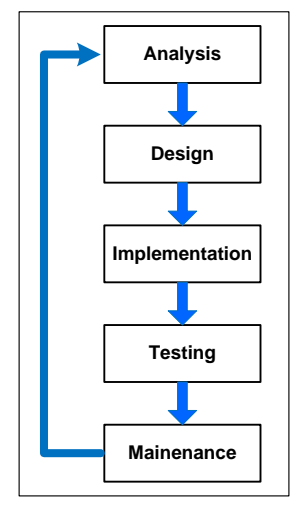

Figure 5: Computer Software Development Life Cycle

At analysis and design stages, the team made decision on the following issues.

1. What game system the team will develop. Considering the lack of coding and software development experience, the team was advised to choose a game that is relatively simple but still contains the major components a game usually has, such as user interaction, scoring sub-system, 3D scene(s), audio/multimedia, and interesting story. The size of the game (software) should be appropriate so that it can be completed within the allotted limit time. With the help of the faculty advisor, the team decided to develop a playable "3D Bowling" game that players can play on computer with mouse and keyboard. This game will integrate many components as an entire computer application, including 3D graphics, multimedia technology (video and audio), programming language, and system integration.

2. What functions/modules the game must have. The major modules this game system should have include (a) 3D object model module, (b) interface module, (c) scoring module, (d) collision detection module, (e) multimedia (audio) module, (f) avatar action module, and (g) ball throwing power management module.

3. What development environment, software and tools the team will use to develop the game. Considering that the team members are the incoming CS freshmen and team members are lack of CS skills, the faculty advisor suggested the team to use Vizard ${ }^{\mathrm{TM}}$ [18], a high-level virtual reality system that allows students faster, easier development of interactive games while they learn the programming concepts and skills behind it. For example, the code snippet consisting of the 11 high-level program sentences as shown in the Figure 6 builds a simple game scene where the background color is set, two avatars are selected from the library, and the female avatar does a 180 degree rotation. Vizard's simplicity and easy use allow the incoming CS freshmen to be able to build a 3D computer game in a short period of time without going through the prolonged and fundamental CS training. 


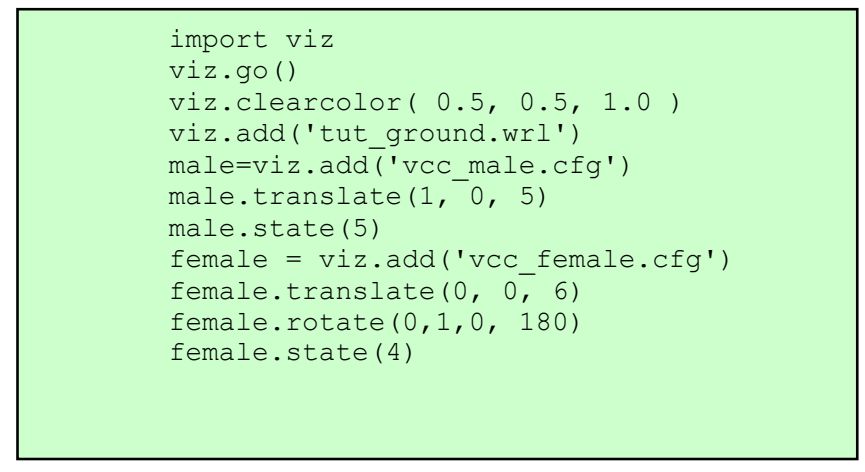

(a)

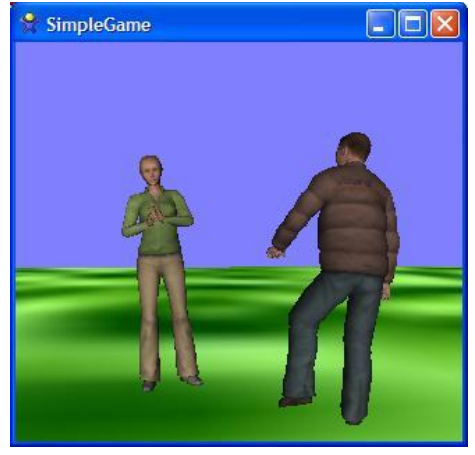

(b)

Figure 6: Vizard Example of a Game Scene: (a) Code; (b) Screen Shot

At the implementation, testing, and maintenance stages, the team learned the high-level 3D game development environment/system, Vizard, computer programming basics, module implementation, and testing skills.

1. Before the implementation, the faculty advisor gave several lectures to introduce basic computer science knowledge to the team and demonstrated how a computer application/software is designed and developed. The topics addressed in this session include presentation on "What is Computer Science?", "Get Your Feet Wet with Basic Computer Programming Language --- Python," "Basic Software Development Skills and Life Cycle," and "Introduction to Game Development, Vizard." After this session, team members took several days to practice Vizard environment and wrote code snippets to learn and test the various Vizard functions, such as 3D object model importing, lighting, shading, texture mapping, camera installation and navigation, avatar features and action, collision detection, physics-based animation engine, 2D/3D audio functions, and so forth.

2. The whole team designed and wrote the specification for each module as a group, and how each module interacts with other modules. Then with the faculty advisor's help, each team member was assigned to implement several modules. Finally, the team worked together to assemble, debug, and test the modules, thus learn how to work and learn from each other as a development team.

3. Inviting fellow summer camping students to test and play the game, collect feedbacks, and polish and finalize the system. Based on the input from the fellow campers, the team removed one function and added several functions to make the game easy to play, and enrich the multimedia module as shown in Figure 7.

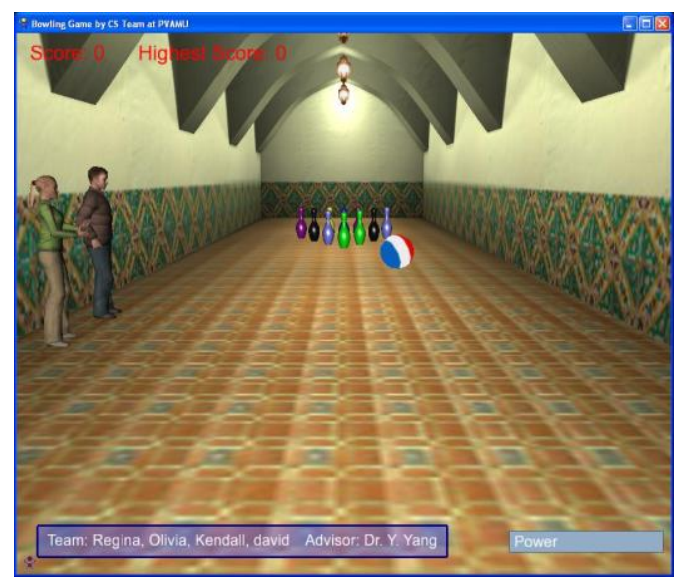

Figure 7: Sample Scene of the Video Game Project 
4. After the system was fully tested, polished, and finalized, the team learned how to document the system, write project report, develop and prepare the final project presentation, and design and produce the final project poster.

Through the three exciting computer-related multimedia projects listed above, the incoming freshmen learned basic computer I/O connection and programming concepts, understood the software development life cycle, enriched their team work experience, and were prepared for the forthcoming four-year college systematic computer study.

\section{CONCLUSIONS}

The COE $\mathrm{CE}^{2} \mathrm{I}$ was a very successful incoming freshmen summer program. The achievements are summarized in five aspects of two categories. One is the overall math, physics, and chemistry enhancement:

1. Upon completion of the program, students were re-administered the Calculus readiness exam and the Chemistry for Engineers placement exam by the respective departments. Based on the results, fall math and chemistry recommended placement was the following: Forty-two students were advanced to Calculus I, of which 20 students were eligible for registration in Honors Calculus I. Two students received Calculus I and/or Calculus II credit from high school and were thus advanced to Calculus II and Differential Equations. With the overwhelming majority of the program participants being recommended for registration in Calculus I, the percentage of students who entered the first semester of their freshman year degree ready (by COE standards) represented approximately 18\% of the freshman class, which is a drastic increase over prior years.

2. Pre-test results from the Chemistry for Engineers exam revealed only four (4) students being eligible to register for this course. Upon completion of the program, twenty students were prepared and eligible to register for Chemistry for Engineers. Eligibility for this course translates to the student not having to take the pre-requisite General Chemistry course, which does not meet degree requirements for any of the programs in the COE.

The other category is the opportunity to work closely with faculty advisors in each program and design hands-on projects:

3. Students gained hands-on experience on real projects of what they can do in the future to benefit the society. They are motivated to complete their course work toward their degree in different programs. Through the project, students also understand that what they learn in the class is tightly linked to our daily lives. As the three example projects unveil the mystery of multimedia techniques through sound, 3D image and video games, students showed interests in multimedia technique and positive feedback was obtained for the three projects. Other incoming freshmen were also attracted to join computer related majors after the end of the camp.

4. Students practiced on teamwork skills. The project gave the students opportunities to work within groups and practice on teamwork skills. To complete the project, students spent every evening on discussion, build, and revise the system together. They realize the importance of collaboration, and everyone must contribute to achieve the goal.

5. This 5-week camp also provides a channel for students to get knowledge of the university, the college, the department, and the labs. They are going to be the seeds we spread to the whole college incoming freshmen. They will lever up the whole quality of our students as a whole. The success of the $\mathrm{CE}^{2} \mathrm{I}$ program is not limited to single project, or how much a student can learn in a 5 week period, but extends the influence to the whole incoming freshmen body.

Preliminary assessment after the first academic year shows that several students achieved a 4.0 and a significant percent of the students achieved a 3.2 or higher GPA, at least four students are participating in summer research experience at other institutions and at least three (3) students participating in corporate intern (2-Lockhead and 1 Bechtel). 
With the achievements in natural science courses, most of the students who participated in the camp shortened their time on courses, will reach engineering knowledge and practices faster. Also, such achievements can help students in building their confidence toward pursuing their engineering degrees. The goal of attracting and retaining more students within the engineering programs has been achieved. Furthermore, the success of program specific hands-on projects give incoming freshmen opportunities getting to know the engineering programs before they even enter the programs. This will benefit students' creation of a positive image on engineering programs and encourage them to stay with such programs to explore more possibilities.

\section{AUTHOR INFORMATION}

Dr. Suxia Cui is an assistant professor in the Department of Electrical and Computer Engineering at Prairie View A\&M University. She received her Ph.D. in Computer Engineering from Mississippi State University in 2003. Her research interests include image processing, video coding, data compression and wavelets. E-mail: sucui@ @vamu.edu

Dr. Yonghui Wang received the Ph.D. degree in computer engineering from Mississippi State University, Starkville, MS, in 2003. He is currently an associate professor with the Department of Engineering Technology, Prairie View A\&M University, Prairie View, TX. His research interests include image and signal processing and image and video coding. E-mail: yowang @ pvamu.edu

Dr. Yonggao Yang is an associate professor and the Interim Department Head in the Department of Computer Science at Prairie View A\&M University. His research interests include computer graphics, scientific visualization and virtual reality, computer animation, distributed virtual environments, and computer networks. He received a Ph.D. degree in information technology from George Mason University in 2002. E-mail: yoyang@ pvamu.edu

Dr. Felecia M. Nave is an associate professor in the Department of Chemical Engineering and Associate Provost \& Associate Vice President for Academic Affairs at Prairie View A\&M University. She received her Ph.D. in Chemical Engineering from University of Toledo, Toledo, Ohio in 2005. Her research interests include membrane and thin film synthesis and characterization for biological separations, factors impacting student success in STEM, and engineering faculty development. E-mail: fmnave@pvamu.edu

Dr. Kendall T. Harris is the Dean of the Roy G. Perry College of Engineering and professor in the Department of Mechanical Engineering at Prairie View A\&M University. He received her Ph.D. degree in Mechanical Engineering from University of Mississippi, Oxford, MS in 1996. His research interests include thermal science, engineering education, and engineering faculty development. E-mail: ktharris@pvamu.edu

\section{REFERENCES}

1. Daniel Hastings, “The Science and Engineering Workforce: Realizing America's Potential,” Natural Science Board, Natural Science Foundation, Aug. 2003. Available at http://www.nsf.gov/nsb/documents/2003/nsb0369/nsb0369.pdf

2. $\quad$ N. Herrmann, et al., "Redesigning introductory computer programming using multi-level online modules for a mixed audience," in Proceedings of 34th SIGCSE Technical Symposium on Computer Science Education, 2003, pp. 196-200.

3. HERI Research Brief, "Degrees of Success: Bachelor's Degree Completion Rates among Initial STEM Majors." Higher Education Research Institute at UCLA, January 2010. Available at http://www.heri.ucla.edu/nih/downloads/2010\%20-\%20Hurtado,\%20Eagan,\%20Chang\%20\%20Degrees\%20of\%20Success.pdf

4. Matthew Ohland, et al., "Persistence, Engagement, and Migration in Engineering Programs" Journal of Engineering Education, Vol. 97, No. 3, July 2008, pp. 259-278.

5. N. Herrmann, et al., "Redesigning introductory computer programming using multi-level online modules for a mixed audience," in Proceedings of 34th SIGCSE Technical Symposium on Computer Science Education, 2003, pp. 196-200. 
6. J. Margolis and A. Fisher, "Unlocking the Clubhouse: Women in Computing”, Cambridge, MA: MIT Press, 2002.

7. ICAF Industries Studies 2006 Report, National Defense University.

8. ICAF Industries Studies 2001 Report, National Defense University.

9. Average ACT Composite Test Scores by Race/Ethnicity 2006-2010, available at http://www.intellectualtakeout.org/library/chart-graph/average-act-composite-test-scores-raceethnicity$2006 \%$ E2\%80\%932010

10. What are the average scores for students taking the SAT? available at http://nces.ed.gov/fastfacts/display.asp?id=171

11. G. Blank, S. Hiestand, and F. Wei, "Overcoming Misconceptions about Computer Science with Multimedia", in Proceedings of $35^{\text {th }}$ SIGCSE Technical Symposium on Computer Science Education, March 2004, Norfolk, VA. Available at http://www.cse.lehigh.edu/ cimel/papers/sigcse04.pdf

12. M. Guzdial, and A.E. Tew, "Imagineering Inauthentic Legitimate Peripheral Participation: An Instructional Design Approach for Motivating Computing Education," in Proceedings of the Second International Computing Education Research Workshop, Canterbury, UK, 2006, pp. 51-58.

13. M. Guzdial and A. Forte. "Design Process for a Non-majors Computing Course," in Proceedings of the 36th SIGCSE technical symposium on Computer science education, St. Louis, Missouri, 2005, pp. 361365 .

14. Y. Wang, S. Cui, Y. Yang, and J. Lian, "Virtual Reality Mathematic Learning Module for Engineering Students," the Technology Interface Journal, vol. 10, No. 1, Fall 2009.

15. S. Cui, Y. Wang, S. Koay, and Y. Yang, "Revamp Computer Education with Multimedia and Game Technologies", 2010 ASEE annual conference and exposition, Louisville, Kentucky, June 20-23, 2010.

16. IEEE Computer Society, ACM, "Computer Engineering 2004: Curriculum Guidelines for Undergraduate Degree Programs in Computer Engineering", December 2004.

17. T. Acharya, and A. K. Ray, "Image Processing - Principle and Applications", Wiley Inter Science.

18. WorldViz Vizard Software, available at: http://www.worldviz.com/products/vizard4/index.html 


\section{NOTES}

